Ensino e Pesquisa

\title{
Professores e suas experiências pedagógicas: estudo sobre a Geografia em um evento de formação continuada no sul do RS
}

\section{Teachers and their pedagogical experiences: study on geography in a continuous training event in the south of RS}

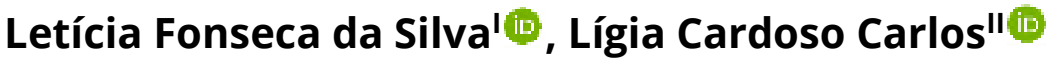 \\ 'Professora da Rede Municipal de Pelotas, Pelotas, RS, Brasil \\ "Universidade Federal de Pelotas, Pelotas, RS, Brasil
}

\section{RESUMO}

O artigo refere-se a uma investigação no âmbito da formação continuada de professores e do ensino de Geografia. Toma como objeto de estudo os anais de doze edições do evento Encontros sobre o Poder Escolar que ocorreram em Pelotas-RS entre os anos de 2001 e 2014 e abrangeram os municípios da região. O objetivo foi conhecer as experiências pedagógicas vinculadas ao campo da Geografia e consideradas de qualidade distintiva pelos professores que as inscreveram, bem como os conteúdos geográficos a elas vinculados. O percurso metodológico, no âmbito qualitativo, foi o da pesquisa documental. Os resultados indicam a disposição da Geografia no atendimento a demandas intra e extraescolares, a peculiaridade de beneficiar práticas interdisciplinares e a ênfase da área ambiental nos trabalhos apresentados.

Palavras-chave: Ensino de Geografia; experiências pedagógicas; formação continuada; formação de professores

\section{ABSTRACT}

The article refers to an investigation in the context of the continuing education of teachers and the teaching of Geography. We took as an object of study the annals of twelve editions of the Encounter on School Power that occurred in Pelotas-RS between 2001 and 2014 and included the municipalities of the region. The objective was to know the pedagogical experiences associated to Geography field and that are considered of distinctive quality by the professors that inscribe them, as well as the geographic contents linked to them. The methodological course, in the qualitative scope, was the documentary research. The results indicate the geography's willingness to attend to intra - and extra - curricular 
2 | Professores e suas experiências pedagógicas: estudo sobre a Geografia em um evento de formação continuada no sul do RS

demands, the peculiarity of benefiting interdisciplinary practices and the emphasis of the environmental area on the presented works.

Keywords: Geography teaching; pedagogical experiences; continuing education; teacher training

\section{INTRODUÇÃO}

O artigo trata de aspectos de uma pesquisa que foi se constituindo a partir de questionamentos em torno da prática dos professores da escola básica, com especial atenção ao ensino de Geografia. Com o propósito de dar visibilidade e examiná-las, buscamos um lócus de investigação com densidade formativa que oportunizasse compreensões sobre a área. Desse modo, tratamos de uma ação de formação continuada de professores da educação básica que se realiza, há quase duas décadas, no sul do estado do Rio Grande do Sul e na qual ocorrem palestras, discussões sobre temas demandados pelos docentes e, também, são compartilhadas e discutidas experiências pedagógicas realizadas nas escolas e consideradas de qualidade distintiva pelos professores que as inscrevem e apresentam. No processo, perguntas foram demarcando a investigação: Quais as propostas de ensino de Geografia presentes nos trabalhos apresentados pelos professores da educação básica? Quais os conteúdos geográficos e as metodologias neles contidos? Quais as áreas dentro do campo da Geografia que se tornaram mais propícias para os docentes desenvolverem práticas pedagógicas consideradas relevantes para serem socializadas com os pares? Entendemos que essa demarcação prenunciou, no desenvolvimento do estudo, disposições pedagógicas no ensino de Geografia que beneficiam alguns enfoques curriculares e metodológicos em detrimento de outros.

Para socializar a investigação, organizamos o texto partindo de uma contextualização da ação indicada acima, que se organiza em torno do evento conhecido como Encontros sobre o Poder Escolar. Buscamos entendê-lo dentro do contexto da formação de professores no país no período de seu início e desenvolvimento. Posteriormente, delimitamos o caminho metodológico adotado, 
apresentamos os dados coletados bem como as discussões teóricas em torno dos resultados e compreensões advindas do processo.

\section{AÇÃO DE FORMAÇÃO “ENCONTROS SOBRE O PODER ESCOLAR" NO CONTEXTO DA FORMAÇÃO DE PROFESSORES}

A formação continuada em análise teve origem e se sustenta no contexto de propostas e estudos do campo da formação de professores no Brasil. Para compreendê-lo é importante observar aspectos da trama social, política e educacional que o abarca. O período de seu início foi o de consolidação do processo de redemocratização do país no momento posterior ao término da ditadura militar, de estabelecimento da nova Lei de Diretrizes e Bases da Educação Nacional promulgada no ano de 1996 e de emergência da discussão e defesa da gestão democrática das escolas.

Circunstâncias que mobilizaram docentes da educação básica e do ensino superior em uma proposta formativa ancorada no entendimento de que os professores podem ser protagonistas de sua formação. Essa premissa dialogava com intelectuais que, no período, produziram e publicaram estudos que influenciaram projetos formativos para a docência. Dentre eles, chamamos a atenção para Nóvoa (1999) que, ao defender a articulação entre as universidades e as escolas no processo formativo, abrangendo a formação inicial e continuada, valorizava a prática profissional realizada no cotidiano da docência como espaço importante de reflexão e investigação. Produção análoga, que teve com sua publicação uma repercussão importante entre intelectuais da área no país, influenciando o debate da formação de professores, foi o texto dos pesquisadores Tardif; Lessard; Lahaye (1991) o qual incluía como saberes da docência aqueles produzidos na prática da profissão, na experiência da ação no interior das escolas. Dando suporte para as discussões sobre a formação docente e presente no projeto que originou o evento em análise, Fullan; Hargreaves (1999) trouxeram para a cena 
as aprendizagens docentes que ocorrem nas trocas, no trabalho colaborativo e em conjunto entre os pares e, desse modo, qualificaram as compreensões sobre a profissão.

No país, intelectuais se debruçaram sobre o tema da formação de professores e consolidaram uma área de estudo que subsidiou o debate e as ações de profissionais e instituições, bem como influenciaram críticas e propostas de políticas públicas. Ressaltamos as discussões sobre a identidade docente e a defesa do fazer pedagógico com potencial de ultrapassar a sala de aula e organizar a escola como instituição democrática e com capacidade de executar projetos político-pedagógicos autônomos (PIMENTA, 1988 e 2000; PARO, 2001). Outro debate importante da época desenvolveu-se questionando as reformas educacionais voltadas para a empregabilidade, as quais submetiam as políticas sociais às políticas econômicas. A crítica a esta lógica (OLIVEIRA, 2008; OLIVEIRA \& DUARTE, 2005; SCHEIBE, 2008) mobilizava buscas por formação pautadas na autonomia e na democracia.

No que se refere especificamente à formação continuada de professores, Gatti (2008) afirmava que o conceito é marcado por imprecisões. Designa cursos de pós-graduação para licenciados ou quaisquer atividades que venham a contribuir no desempenho profissional. Teve um aumento de sua oferta a partir do final da década de 1990, principalmente nas regiões sul e sudeste do Brasil, em formato bastante heterogêneo e respondendo a uma necessidade de qualificar a formação docente na perspectiva de atender a reformas curriculares orientadas por demandas do mundo do trabalho e minimizar o baixo desempenho escolar.

Nesse contexto, o projeto Encontros sobre o Poder Escolar foi registrado na Universidade Federal de Pelotas (UFPEL) como extensão universitária e teve seu início no ano de 2001, a partir de demandas por formação continuada de professores da rede básica. Para dar conta do intento, foi se constituindo uma parceria entre sete instituições: Faculdade de Educação da UFPEL, Universidade 
Católica de Pelotas (UCPEL), Instituto Federal Sul Riograndense (IFSul-RS), Conselho Municipal de Educação de Pelotas, Secretaria Municipal de Educação de Pelotas, $5^{a}$ Coordenadoria Regional de Educação do Estado do RS e $24^{\circ}$ núcleo do Centro dos Professores do Estado do Rio Grande do Sul (CPERS-Sindicato). O objetivo principal foi a formação continuada de professores que atuavam em escolas públicas de educação básica, prioritariamente. Cada edição do evento teve carga horária de quarenta horas distribuídas em quatro dias de trabalhos. Houve uma significativa participação de professores das escolas de Pelotas e demais municípios do seu entorno, bem como uma participação do campo da Geografia em todas as edições como mostra o quadro 1, abaixo:

Quadro 1 - Inscritos e experiências nos anais do evento Encontros sobre o Poder Escolar referentes a Pelotas/RS e municípios do seu entorno no período de 2001/2014

\begin{tabular}{|cccc|}
\hline Evento/Ano Inscritos & $\begin{array}{c}\text { Experiências } \\
\text { pedagógicas nos } \\
\text { anais }\end{array}$ & $\begin{array}{c}\text { Experiências } \\
\text { pedagógicas } \\
\text { Geografia }\end{array}$ \\
\hline $1^{\circ} 2001$ & 1200 & 30 & $5(16,6 \%)$ \\
$2^{\circ} 2002$ & 1400 & 26 & $4(15,3 \%)$ \\
$3^{\circ} 2003$ & 1300 & 24 & $11(45,8 \%)$ \\
$4^{\circ} 2004$ & 1800 & 100 & $12(12 \%)$ \\
$5^{\circ} 2005$ & 1541 & 158 & $17(10,7 \%)$ \\
$6^{\circ} 2006$ & 1458 & 139 & $14(10 \%)$ \\
$7^{\circ} 2007$ & 1700 & 142 & $13(9,1 \%)$ \\
$8^{\circ} 2008$ & 1646 & 140 & $18(12,8 \%)$ \\
$9^{\circ} 2009$ & 1652 & 155 & $13(8,3 \%)$ \\
$10^{\circ} 2010$ & 1545 & 148 & $13(8,7 \%)$ \\
$11^{\circ} 2012$ & 1512 & 145 & $14(9,6 \%)$ \\
$12^{\circ} 2014$ & 800 & 174 & $9(5,1 \%)$ \\
\hline
\end{tabular}

Fonte: Organização das autoras (2018).

Nota: No período da coleta de dados os anais da $13^{a}$ edição do evento não estavam publicados. Em 2019 ocorreu a $14^{a}$ edição do evento.

A proposta de formação continuada em formato de evento teve uma intenção política de dar visibilidade aos saberes que são construídos na ação 
profissional, no chão das escolas de ensino básico. Nele os professores são protagonistas da formação quando socializam e discutem as experiências escolares na forma de trabalhos inscritos para serem apresentados aos pares. Foi organizada em oposição a um discurso vigente que atribuía - e ainda atribui - aos professores e suas práticas pedagógicas as mazelas presentes nas escolas. Desse modo foram preparados os Encontros sobre o Poder Escolar, pautados na valorização do trabalho docente cotidiano, dos projetos pedagógicos promovidos e realizados no interior das escolas e no fortalecimento da gestão escolar democrática. Nas mesas de apresentação de experiências pedagógicas os professores socializam e discutem suas práticas cotidianas e produzem compreensões sobre o trabalho docente. A expectativa é de que esses saberes sejam qualificados e ampliados nas trocas, contribuindo nas ações da sala de aula e da gestão escolar. As palestras, conferências e oficinas compõem o processo e devem proporcionar diálogos formativos.

A pesquisa se deteve nas experiências pedagógicas inscritas e apresentadas pelos professores e que foram registradas nos anais do evento, focando naquelas vinculadas ao ensino de Geografia e temáticas afins.

Atuaram como interlocutores basilares na discussão dos dados Tardif (2014), Shulman (2014) e Sacristan (1999) no que se refere aos saberes da profissão docente e Cavalcanti $(2006$; 2013) no que se refere ao ensino de Geografia.

\section{CAMINHOS METODOLÓGICOS}

O estudo foi desenvolvido tendo como base a pesquisa qualitativa que, segundo Angrosino (2009), consiste em abordar o mundo lá fora para entender, descrever e explicar os fenômenos sociais de dentro. O percurso metodológico adotado foi o da análise documental (PIMENTEL, 2001; CORSETTI, 2006), por meio do qual investigamos os anais publicados das edições realizadas do evento Encontros sobre o Poder Escolar e que contém os resumos de trabalhos inscritos, 
na sua maioria, por professores da Educação Básica e tratam de experiências pedagógicas produzidas no exercício da profissão.

Foram analisados os doze anais publicados do evento Encontros sobre o Poder Escolar no período da coleta de dados, percorrendo os anos de 2001 a 2014 e, neste sentido, o estudo pode ser considerado como de tipo estado do conhecimento da Geografia escolar presente nas experiencias pedagógicas inscritas no evento por professores da educação básica. Como estratégia de aproximação com os dados foi realizada uma primeira leitura de todos os resumos contidos nos anais e selecionados os que tinham uma referência explícita à disciplina escolar Geografia, indicadas pelos autores, bem como aqueles que, mesmo não tendo uma referência nominal à área no seu título ou no eixo no qual o trabalho foi inscrito, pertenciam ao campo dos estudos em Geografia. Depois, os resumos inicialmente selecionados passaram por uma segunda leitura, da qual foram extraídas informações sobre as estratégias de ensino utilizadas, os conteúdos curriculares enfatizados e as áreas do ensino de Geografia privilegiadas. Cabe ressaltar que, por lidarmos com resumos, as informações fornecidas eram reduzidas, porém, suficientes para o propósito de conhecer as experiências pedagógicas vinculadas ao campo da Geografia e consideradas de qualidade distintiva pelos professores que as inscreveram, bem como os conteúdos geográficos a elas vinculados.

\section{OS DADOS DO ESTUDO}

Nessa seção serão apresentados aspectos dos trabalhos selecionados, no que tange ao campo da Geografia, a partir de cada edição do evento Encontros sobre o Poder Escolar. Importante considerar que cada edição tinha um fio condutor, uma ênfase que pautava a organização e era anunciada na divulgação. Conforme Silva e Dalligna (2018), estes fios condutores estavam presentes na valorização do trabalho docente cotidiano, no reconhecimento dos projetos 
pedagógicos promovidos e realizados no interior das escolas e na relevância da gestão escolar democrática. Indicavam a tendência político-pedagógica da proposta ao longo dos anos e o contexto no qual os professores inscreveram suas experiências profissionais. Neste sentido, importante ressaltar que o evento estava em sintonia com os estudos e discussões sobre a formação continuada no país, conforme já indicado no texto, as quais tratavam da identidade docente, da escola como instituição democrática, das críticas às reformas educacionais voltadas para o mercado e para a empregabilidade e da autonomia e valorização da formação por dentro da profissão.

Abaixo, considerações sobre as experiências pedagógicas incluídas no estudo e voltadas para o campo da Geografia. Apresentam algumas características descritivas, porém, necessárias para compreender a formação docente. São apresentadas em quatro blocos, contendo três eventos em cada um deles.

\section{$4.11^{\circ}, 2^{\circ}$ e $3^{\circ}$ Encontros sobre o Poder Escolar (2001 a 2003)}

Os registros publicados nos anais dos três eventos iniciais apresentam a programação, bem como os texto das conferências que, pelo seu conteúdo, estavam ligadas a pesquisas acadêmicas voltadas à formação docente. Pela informação verbal de professores membros da comissão organizadora, os relatos de experiências, nos dois primeiros eventos, partiram de convites feitos aos professores da educação básica identificados pelos pares como responsáveis por boas práticas no campo educativo regional e, a partir do terceiro, foram abertas inscrições para submissão de trabalhos. As conferências, palestras e mesas de discussão atenderam aos temas que entraram em voga em meados dos anos de 1990 no Brasil, ou seja, direitos humanos, educação ambiental, projeto políticopedagógico, democracia e gestão escolar, educação das relações étnico-raciais, inclusão e sexualidade. 
O registro das experiências pedagógicas das escolas, apresentadas nesses três primeiros eventos, ficaram restritas ao título e autoria nos anais, uma vez que não foram publicados os seus referidos resumos. No primeiro evento foi possível aferir títulos vinculadas ao campo da Geografia e que indicavam estudos em educação ambiental, composição étnica e agricultura no RS e imagens do Brasil através da fotografia. No $2^{\circ}$ Encontro sobre o Poder Escolar foram selecionadas para análise desta pesquisa títulos indicando a leitura de paisagens brasileiras através da fotografia e o tema transversal da educação ambiental. Na terceira edição do evento, as experiências destacadas tratavam de assuntos relacionados à Geografia e meio ambiente - produção de lixo e reciclagem, recursos hídricos e modos de representação do espaço - e, ainda relacionados ao campo da didática e da formação do docente de Geografia.

\section{2 $4^{\circ}, 5^{\circ}$ e $6^{\circ}$ Encontros sobre o Poder Escolar (2004 a 2006)}

A partir do quarto evento, ano de 2004, o encontro foi ampliado de forma significativa como mostra o quadro 1. A interdisciplinaridade foi a tônica das experiências, inclusive sendo considerada pelos organizadores do evento como uma dificuldade no processo de selecionar, agrupar e organizar as apresentações por áreas de estudo e interesse.

Merece destaque o fato de muitos projetos apresentados constituíremse em trabalhos conjuntos, seja entre professores de diferentes disciplinas seja entre professores de mais de uma escola na busca da interdisciplinaridade. Isto inclusive tornou difícil a organização das mesas de apresentação de experiências. (ENCONTRO SOBRE O PODER ESCOLAR - ANAIS, 2004, p. 02)

As experiências de Geografia selecionadas enfatizaram a valorização da formação cultural dos espaços através de pesquisas, saídas de campo e leitura de imagens, destacando a influência açoriana e alemã na região sul do Rio Grande do Sul, as mudanças do espaço geográfico no capitalismo e o estudo do bairro. 
Os demais resumos tratavam de práticas escolares organizadas para as séries iniciais e enfatizavam as problemáticas da produção do lixo e o incentivo à reciclagem. Também, a preservação de espécies da flora e da fauna. Entendemos que os temas revelam a disposição em cumprir com a interdisciplinaridade presente nos projetos pedagógicos das escolas, os quais passaram por reformulações no início dos anos 2000. As atividades propostas pelos professores vincularam poesias, literatura, músicas e construção de hortas.

No $5^{\circ}$ Encontro sobre o Poder Escolar, as temáticas e os conteúdos da Geografia que se sobressaem são aqueles ligados à Geografia Física, com o estudo de rios e relevo, e à Geografia Econômica, com reflexões sobre atividades produtivas e suas consequências na realidade local e vinculação com assuntos globais. Também, análise da cultura local, salientando seu potencial turístico e econômico.

As experiências entendidas por nós como em interface com a Geografia, são de trabalhos interdisciplinares que utilizaram estratégias de pesquisas escolares como forma de reflexão dos problemas do meio ambiente que assolam a sociedade. Por fim, propõem ações que levam aos cuidados com o ambiente envolvendo a comunidade na qual a escola está inserida como: práticas de reflorestamento, passeatas ecológicas e a conscientização para a coleta seletiva do lixo, tão pouco realizada nas periferias urbanas do município de Pelotas.

$\mathrm{Na} 6^{\circ}$ edição do evento as experiências têm ênfase em assuntos que fazem parte dos conteúdos curriculares da Geografia. São relatos de ações em projetos de formação continuada de professores promovidos pelas secretarias municipais de educação e universidades, em parcerias com os professores da rede básica. Os resumos mencionam os conteúdos geográficos quando abordam a poluição do ar e da água, o aquecimento global e o acúmulo do lixo resultante de uma sociedade consumista, fazendo uma análise da mudança dos espaços em curto período. Nesses projetos, a Geografia não faz reflexões sozinha, dialoga com as demais 
disciplinas para promover debates que buscam a sensibilização para problemas ambientais locais. As escolas rurais também estavam representadas com oficinas envolvendo a comunidade escolar na busca da conscientização ambiental com vistas a uma melhor qualidade de vida. Os resumos demonstraram o modo como estratégias metodológicas com o uso de mídias puderam potencializar o aprendizado dos alunos, incrementando as aulas mais convencionais.

\section{3 $7^{\circ}, 8^{\circ}$ e $9^{\circ}$ Encontros sobre o Poder Escolar (2007 a 2009)}

Nos anais do $7^{\circ}$ Encontro sobre o Poder Escolar, novamente, observamos um importante número de trabalhos descrevendo projetos oriundos de "fora para dentro" da escola, ou seja, relatos de ações oriundas de projetos da Secretaria Municipal de Educação de Pelotas para as escolas do município e das universidades da região para as escolas. Nos relatos relacionados aos conteúdos geográficos, estavam presentes:

- Trabalhos em grupos e interdisciplinares voltados para as potencialidades locais, tanto no que se refere aos aspectos físicos como a vegetação, os recursos hídricos e o relevo, como na valorização da cultura da região manifestada nas charqueadas e na imigração;

- Propostas de trabalhos de pesquisa e exposição dos mesmos à comunidade. Os docentes relatam que para tornar os conteúdos significativos deve haver um misto de teoria, observação in loco e sistematização dos conhecimentos adquiridos. Foram ressaltados o acúmulo de lixo, a poluição das águas, o uso indiscriminado de agrotóxicos e o aquecimento global;

- Discussão de temas da Geografia com o uso de filmes, documentários e leitura de imagens.

Quanto aos anais do $8^{\circ}$ Encontro sobre Poder Escolar, pudemos observar, assim como no anterior, experiências de formação inicial e continuada de professores vinculadas às instituições de ensino superior da região. A palavra 
interdisciplinar e transdisciplinar segue em voga nos resumos, bem como a Educação Ambiental. Os relatos que foram selecionados, na sua grade maioria, apontam para trabalhos com a construção de hortas e jardins nas escolas, assim como ações de incentivo à coleta seletiva do lixo e sua destinação adequada. Indicam uma valorização dos espaços rurais e de práticas agroecológicas, dando vazão para os saberes empíricos da comunidade escolar.

As estratégias metodológicas propostas pelos professores acompanham uma lógica de pesquisa pela observação, tomada de consciência pela reflexão através de sistematizações em textos, cartazes ou maquetes e pequenas ações locais para a mudança de hábitos. Quando trabalhados de forma interdisciplinar, envolvem as disciplinas de Geografia, Química e Física, preponderantemente. Temas relevantes como aquecimento global e efeito estufa são atrelados à problemática do crescente volume de lixo produzido nas cidades.

As experiências que tratam da Geografia de forma mais específica procuraram problematizar as transformações do espaço geográfico a partir da observação e da investigação sobre o passado. Além de resgatar valores humanos e ambientais, os relatos indicaram temas como a utilização dos espaços agrícolas, posição solar, relevo, quantidade e qualidade da água. Também estava presente um trabalho sobre a África e a negritude brasileira, fazendo um paralelo geográfico entre os continentes.

No $9^{\circ}$ Encontro, assim como nos dois eventos anteriores, notamos que muitos trabalhos apresentados tratam de projetos de pesquisa e extensão de instituições de ensino superior da região. Também integram projetos com parcerias de órgãos governamentais como a Empresa Brasileira de Pesquisa Agropecuária (EMPRAPA), a Empresa de Assistência Técnica e Extensão Rural (EMATER) e a Secretaria de Qualidade Ambiental do município de Pelotas.

A maioria dos trabalhos se referem ao tema transversal da Educação Ambiental, com o qual é possível analisar paisagens, suas transformações e 
apontar para um ambiente mais saudável, independente do grau de escolaridade dos alunos. Através do projeto de Hortas Orgânicas, por exemplo, os docentes relatam que articulam a posição solar, a qualidade do solo, os cálculos matemáticos, o resgate da cultura local e hábitos mais saudáveis de alimentação nas escolas.

A Geografia se integra com facilidade com as disciplinas de Ciências, História, Filosofia e Arte nas atividades interdisciplinares. Alguns relatos abordam o mundo do trabalho e o problematizam com assuntos em voga no momento, dando enfoque para as possíveis soluções para a produção crescente do lixo diante do alto grau de consumismo no final do século XX e início do século XXI no Brasil.

As metodologias que aparecem nos trabalhos de Geografia seguem uma sequência de apresentação de conceitos pelos docentes, pesquisas em fontes escritas e de mídias digitais, observações empíricas em saídas de campo e sistematização dos conhecimentos em redações, painéis, maquetes ou trabalhos dramatizados através do teatro ou música.

\section{4 $10^{\circ}, 11^{\circ}$ e $12^{\circ}$ Encontros sobre o Poder Escolar (2010, 2012 e 2014)}

Os documentos utilizados como fonte de dados foram os anais dos três últimos eventos publicados no período da coleta de dados. Observamos, primeiramente, o pequeno número de trabalhos abordando a disciplina de Geografia de modo isolado, bem como um número significativo de trabalhos ressaltando projetos interdisciplinares envolvendo a História, a Língua Portuguesa, a Arte e a Educação Ambiental, vinculando valores humanos, letramento, mídias, tecnologia e culturas locais. Muitos deles vinculados a datas comemorativas específicas ou temas da atualidade.

Nos anais do $10^{\circ}$ Encontro sobre Poder Escolar observamos que as experiências pedagógicas selecionadas, na sua maioria, estavam ligadas a projetos que tratavam de temas transversais do currículo escolar. Segundo os registros, 
foram executadas por coletivos de profissionais e não individualmente, estavam ligadas a assuntos da atualidade como consumo de alimentos orgânicos, relações étnico-raciais, educação inclusiva, inclusão digital e preservação ambiental. Identificamos a intenção dos professores em apresentar aos seus alunos a rápida transformação do espaço, dando enfoque à degradação ambiental por meio do consumo exagerado da sociedade moderna, apontando, através de diferentes ferramentas, ações com vistas a sustentabilidade. Os resumos indicavam o incentivo às práticas agroecológicas, à coleta seletiva do lixo, à construção de hortas escolares, à valorização das plantas medicinais e da cultura local.

Os resumos que trazem os saberes geográficos de modo específico foram dois e vinculados a estágios supervisionados, um do curso de Pedagogia e outro da licenciatura em Geografia. O relato do estágio de Pedagogia evidencia a preocupação com a alfabetização cartográfica e o uso do software Google Earth para dar conta das dificuldades de abstração que os alunos apresentam nas séries iniciais. Já o estágio de Geografia trata da construção do conceito de espaço geográfico utilizando recursos simples como figuras de revistas antigas e imagens atuais. Ambos contemplam os conteúdos que foram previamente planejados e fazem parte do currículo escolar orientado pelos Parâmetros Curriculares Nacionais em vigência no período.

As experiências selecionadas do $11^{\circ}$ Encontro sobre Poder Escolar pouco se referem aos conteúdos específicos da disciplina Geografia presente no currículo escolar. As ações pedagógicas que os docentes entenderam importantes para serem socializadas no evento se desenvolveram vinculadas à busca da consciência ambiental. Para tal, os professores utilizaram ferramentas multimídias, contextualizando a grande quantidade de informações trazidas pela acessibilidade dos meios de comunicação e transformando-as em conhecimento geográfico. No $12^{\circ}$ Encontro sobre o Poder Escolar continuaram em evidência as práticas pedagógicas vinculadas às questões ambientais. As estratégias apontadas pelos 
docentes tiveram enfoque na preocupação com as mudanças climáticas e com a necessidade de alterações comportamentais em relação ao meio em que os alunos estão inseridos, procurando ações mais sustentáveis. Um resumo apresenta possibilidades do ensino de Geografia para a educação inclusiva, atendendo crescente demanda verificada nas escolas nos últimos anos, e outro trata da valorização do patrimônio histórico e cultural em interface com a construção de saberes geográficos.

\section{COMPREENSÕES DO PROCESSO}

Buscando caminhos de discussão dos dados, entendemos que as experiências pedagógicas inscritas pelos professores e publicadas nos anais no formato de resumos indiciam o que afirma Tardif (2014):

[...] múltiplas articulações entre a prática docente e os saberes fazem dos professores um grupo social e profissional cuja existência depende, em grande parte, de sua capacidade de dominar, integrar e mobilizar tais saberes enquanto condições para a sua prática. (TARDIF, 2014, p.39)

Ao tratar de saberes da docência, o autor refere-se aos saberes da formação profissional, saberes disciplinares, saberes curriculares e saberes práticos. $\mathrm{Na}$ mesma obra, indaga se os professores, como categoria profissional, não deveriam "se impor como uma das instâncias de definição e controle dos saberes efetivamente integrados à sua prática" (TARDIF, 2014, p.39). Sua resposta é desafiadora ao indicar que os saberes da formação, disciplinares e curriculares se incorporam à prática, porém, não são legitimados ou efetivamente produzidos a partir dela, ou seja, a ação docente cotidiana se constitui no conjunto dos saberes não se impondo a eles. Nessa perspectiva, os professores socializam suas práticas através do evento e mostram como mobilizam saberes e os ampliam na troca com os pares, ora buscando estratégias de ensino e aprendizagem para situações costumeiras, ora lidando com situações da sociedade em uma dimensão mais ampla, as quais se apresentam como desafios - como no caso da inclusão escolar 
e da degradação do meio ambiente. Mesmo considerando os limites dos professores na relação com os saberes da profissão, os dados mostram possibilidades de redimensionamento da prática pedagógica em situações imediatas de ensino que desacomodam a cultura escolar e curricular local, potencializando compreensões sociais e políticas mais alargadas.

Os trabalhos que revelam atividades que indicamos como de "fora para dentro" da escola, com a inserção de temáticas da educação ambiental nas atividades pedagógicas, oriundas, em boa parte, de exigências e proposições de secretarias de educação e parcerias interinstitucionais - firmadas, geralmente, sem a anuência das escolas - indicam a relativa autonomia político-pedagógica dos docentes em produzir saberes e fazeres pautados nas suas compreensões e decisões teórico-práticas. Embora sejam temas da realidade das comunidades escolares, se pautam em projetos construídos fora do lócus da escola, circunscritos pela influência dos Parâmetros Curriculares Nacionais enquanto parte da política educacional nacional gestada na segunda metade dos anos 1990 no país.

Sacristán (1999) contribuiu na compreensão do processo na medida em que trouxe para o debate o enunciado de que as práticas não se reduzem às ações dos professores, mas, a contextos incluídos uns nos outros. Ao buscar definir a profissionalidade docente, o autor declara que elas só podem ser entendidas enquanto parte do debate sobre o sistema escolar e estão em permanente elaboração, dependendo do seu momento histórico e da realidade social que o conhecimento escolar pretende legitimar. Desse modo, o autor nos indica que as ações docentes na prática escolar vão além do domínio de conhecimentos científicos e metodológicos que advém da formação acadêmica, estão vinculadas a outros sistemas e práticas concorrentes que, nem sempre, caminham no mesmo sentido. Assim, "a política educativa é, de alguma forma, uma sugestão e uma imposição de práticas, tanto maior quanto mais intervencionista for nos processos 
pedagógicos e quanto menos capacidade de contestação, réplica e participação tiverem os professores" (SACRISTÁN, 1999, p.74).

Dando seguimento a este raciocínio, é possível identificar que a Geografia integra as experiências docentes presentes nos anais considerando tanto as exigências do currículo escolar como as demandas externas. Ainda dialogando com Sacristán (1999, p.69), "existe uma prática educativa e de ensino, em sentido antropológico, anterior e paralela a escolaridade própria de uma determinada sociedade ou cultura" e é nesse contexto que as práticas profissionais escolares se desdobram. Nem todas as dimensões da prática pedagógica são visíveis, há o que os docentes consideram útil e deve ser priorizado para determinado grupo social, há normas de comportamento e valores sociais, há exigências institucionais e possibilidades vinculadas ao espaço e ao tempo do sistema escolar. Nessa perspectiva, apresenta-se nas escolhas dos docentes e em suas experiências pedagógicas socializadas nos eventos um sistema de práticas aninhadas, vários contextos abarcados uns nos outros que configuram ações e decisões na profissão.

Ao observarmos as experiências contidas nos anais, buscando aquelas que tratam do campo da Geografia, identificamos uma seleção de assuntos nos currículos da educação básica que se prestam para dar vazão a práticas menos convencionais, mais significativas e, portanto, dignas de serem inscritas no evento. Os dados mostram que temáticas ligadas à Educação Ambiental e, consequentemente, à Geografia Ambiental são as mais valorizadas. Nesse contexto, ficou manifesto que os professores investem em práticas consideradas de qualidade distintiva articulando estratégias que contemplam assuntos em voga com os conteúdos curriculares, através de uma mobilização interna, da criatividade e dos recursos de cada um. A maneira como esses saberes da prática são constituídos e podem instrumentalizar o professor não está sistematizada, mas está nos exemplos, no conhecimento empírico, na história de vida dos profissionais da educação básica. Segundo Tardif (2014, p.58), “[...] os trabalhadores desenvolvem, progressivamente, saberes gerados e baseados no 
próprio processo de trabalho. Ora, são exatamente estes saberes que exigem tempo, prática, experiência, hábito, etc."

Assim, a Geografia participa do processo formativo de modo preponderantemente interdisciplinar e encontra nos temas vinculados ao meio ambiente um espaço propício para desenvolver processos de ensino e aprendizagem dos conteúdos geográficos, cumprindo as exigências dos currículos escolares. Aqueles que têm uma maior representatividade nos relatos dos docentes estão ligados ao estudo das características naturais como clima, vegetação, hidrografia, relevo e os impactos decorrentes da ação antrópica, porém, ao apresentá-los vinculados com a reflexão ambiental, trabalham também questões políticas, econômicas, culturais e sociais. Como já indicado, eles são considerados significativos quando trabalhados no espaço escolar junto com outras disciplinas, em projetos amplos e compondo atividades extraclasse. Entre as atividades apresentadas, estão em evidência aquelas ligadas ao lúdico e à inclusão digital, principalmente no que se refere à observação das paisagens degradadas com vistas a uma consciência ambiental e mudanças de comportamento local. Entre as metodologias e estratégias adotadas nas atividades propostas e apresentadas pelos docentes, estão as ferramentas digitais, a utilização de imagens, a música, a dança, as brincadeiras e gincanas, sessões de vídeo e observações in loco.

Compreendemos que o meio em que o professor está inserido, seus vínculos sociais, sua história de vida, sua formação acadêmica e, principalmente, a reflexão sobre suas práticas permitem uma relativa autonomia para construir estratégias diárias e lidar com os desafios do trabalho escolar. Desse modo, reconhecemos a produção de um saber que vai se constituindo ao longo da trajetória profissional. Aliada a esses processos, o registro das experiências docentes pode se constituir como ferramenta para reflexão, reformulação e definição das práticas docentes. Conforme Shulman (2014): 
O grande desafio dos profissionais que desejam aprender pela experiência é a dificuldade de conservar as experiências na memória em formas que possam ser objetos de análise disciplinada e de reflexão. Considere a possibilidade de que os casos são formas de análise da experiência, de forma que os práticos possam examinar e aprender a partir deles. (...) Métodos de casos, assim, se tornam estratégias para ajudar professores a 'agrupar' suas experiências em unidades que podem se tornar o foco para a prática reflexiva. Podem se tornar a base para aprendizagem individual do professor, assim como uma forma com a qual comunidades de professores, tanto local como mais ampliada, podem armazenar, trocar e organizar suas experiências. (SHULMAN, 2014, p.199)

Levando em conta a ideia de Shulman (2014) de que os registros são valiosos modos de análise e problematização das práticas, potencializando a formação entre os pares e a autoformação, é que os resumos dos anais foram considerados. Porém, os registros neles presentes contêm justificativas pela escolha de determinado tema e estratégias, se ausentando de informações ou indícios sobre os raciocínios pedagógicos envolvidos no ensino dos conteúdos curriculares ou intencionalidades vinculadas aos processos de aprendizagem mais específicos. Desse modo, ou os professores não registraram seus juízos e proposições devido ao formato exíguo de resumo, ou não exercitaram de modo suficiente os raciocínios pedagógicos que, no nosso entendimento, compõem a profissionalidade docente.

Consideramos importante destacar que a existência de uma cultura enraizada de não realizar registros mais reflexivos das ações docentes, conforme já elucidado por Shulman (2014), aliada à identificação de planejamentos como tarefas burocráticas e marcadas pela cultura tecnicista em educação da década de 1970, pode inibir a socialização com os pares a partir das escritas. Além disso, ressaltamos a possibilidade de um julgamento antecipado, por parte dos docentes, de que os raciocínios que antecedem e acompanham as práticas profissionais cotidianas são corriqueiros e não possuem uma singularidade e pertinência merecedoras de visibilidade e com potencial formativo para os demais. 
No que se refere ao formato interdisciplinar das experiências contidas nos anais e selecionadas para nosso estudo, importante considerar a atuação de investigações sobre o tema da interdisciplinaridade na formação de professores nos anos1990 e início dos anos 2000 (FAZENDA, 1993 e 1998; LUCK, 2001), influenciando as escolhas pedagógicas e o trabalho nas escolas. Nessa circunstância, encontramos uma Geografia que se constituiu no diálogo com diferentes áreas do conhecimento e através de variadas formas de linguagem e gêneros de texto, sendo parceira na busca de compreensões sobre temáticas que extrapolaram as grades curriculares mais formais e foram receptivas aos sentidos dados pelos alunos às suas práticas espaciais.

Essas atividades interdisciplinares com a participação do campo de estudos da Geografia vão ao encontro do que considera Cavalcanti (2006) sobre o ensino diante da experiência da globalização. A autora observa que há uma nova cultura e espacialidade, demandando outras formas de entendimento e análise, trazendo novas exigências para a área. A vida cotidiana se torna mais complexa e os conteúdos mais convencionais do currículo não a acompanham, sendo imperativo lançar mão de dispositivos que possibilitem reconhecimentos mais críticos e relacionais, bem como alterações na formação docente para dar conta dos desafios que se impõem.

Conforme a autora:

Para que os alunos entendam os espaços de sua vida cotidiana, que se tornaram extremamente complexos, é necessário que aprendam a olhar, ao mesmo tempo, para um contexto mais amplo e global, do qual todos fazem parte, e para os elementos que caracterizam e distinguem seu contexto local. [...] deve-se levar em consideração, portanto, o local, o lugar do aluno, mas, visando propiciar a construção pelo aluno de um quadro de referências mais gerais que lhe permita fazer análises mais críticas desse lugar. (CAVALCANTI, 2006, p. 32).

O desafio do ensino da Geografia permanece sendo o de ampliar a capacidade crítica na ação pedagógica de maneira que os alunos possam participar 
mais amplamente dos processos de ensino e aprendizagem. Para desenvolver saberes necessários a um bom professor, sobretudo, um bom professor de Geografia, Cavalcanti (2013) defende um contexto no qual a relação alunoprofessor possa evidenciar outra forma de produzir os conhecimentos geográficos escolares, baseada em uma postura renovada de mais diálogo e entendendo que o aluno faz parte da ação pedagógica. Porém, a autora chama a atenção para o fato de não deixar a geografia escolar lidar somente com o empírico, com o mundo da vivência, mas com o mundo como objeto de pensamento, ou seja, "é necessário que o professor ajude os alunos a compreenderem o processo de conhecimento científico levando-os além de seu mundo cotidiano" (CAVALCANTI, 2013, p.54).

Entendemos que a geografia do dia a dia dos alunos - o espaço vivido - com a geografia científica e o espaço concebido por ela, tem o potencial de reelaborar conceitos e ampliar a compreensão das experiências cotidianas. Então, não basta trabalhar com os conteúdos escolares formais, é necessário, no encontro de ambas, buscar significados e sentidos que os alunos dão aos temas nos quais os conteúdos estão presentes. Implica considerar não somente o cognitivo, mas, as dimensões sociais, culturais e subjetivas articuladas nas experiências de vida. Os resumos presentes nos anais investigados não explicitam o trabalho com categorias de análise como natureza, ambiente, lugar ou território para a construção de um pensamento espacial, mas, possibilitam vivências, muitas delas interdisciplinares, que encaminham compreensões de base para a formação de conceitos.

Nesse processo de formação continuada que não é pontual, visto o seu tempo de existência, circunstâncias sociais, políticas, culturais e econômicas foram determinantes, atravessaram e movimentaram as ações pedagógicas e de gestão das comunidades escolares. A junção dessas circunstâncias foi produzindo fazeres e saberes, adesões e supressões, práticas e concepções de ensino e aprendizagem demarcadas pela maneira como os sujeitos envolvidos entendem os outros, a si mesmos e a sociedade. 


\section{CONSIDERAÇÕES FINAIS}

Entendemos que conhecer as iniciativas de formação continuada que se iniciam e se desenvolvem fora dos grandes centros urbanos, das capitais e dos eixos de maior visibilidade no país contribui para ampliar e aprimorar nossas compreensões sobre a profissão, sobre o trabalho docente e suas possibilidades.

Sustentamos que os docentes criam uma disposição para investir na profissão quando têm suas experiências reconhecidas e entendidas como contributos para a formação. Deste modo, os espaços de socialização e discussão de práticas e projetos escolares com os pares, nos Encontros sobre o Poder Escolar, evidencia a importância do diálogo pedagógico para a formação e para a articulação e fortalecimento dos saberes da profissão. Com o estudo foi possível reiterar que o processo de formação é permanente e se amplia com possibilidades de socialização e discussão, podendo servir de base teórico-prática para a formação inicial, estreitando as relações entre universidade e escola. A possibilidade de conhecer as práticas dos professores, as interferências com as quais estão lidando e as estratégias curriculares utilizadas e expressas no cotidiano, através da apresentação de experiências no evento, mostra as implicações entre saberes disciplinares e pedagógicos e as possíveis ressignificações engendradas nos contextos escolares.

Os resumos não somente mostraram as práticas consideradas mais significativas para serem socializadas, mas, também, delinearam os problemas socialmente relevantes naquelas escolas. Assim, expressaram a composição do currículo escolar na trama entre conteúdos oficiais, demandas sociais e interesses da comunidade escolar. A ênfase em iniciativas referentes aos temas ambientais e ao recurso de trabalhos interdisciplinares estavam presentes tanto por terem sido fomentadas pelas secretarias de educação e instituições de formação, quanto por darem vazão a práticas pedagógicas menos convencionais, tratando de situações do mundo da vida e do trabalho que vão ao encontro das vivências, 
carências e percepções das comunidades escolares. Os resumos analisados também indicaram que o registro das atividades docentes para inscrição e apresentação das experiências pedagógicas no evento constituem ferramentas de reflexão e formação com os pares, mesmo que não informem os raciocínios pedagógicos realizados no trabalho docente, como trata Shulman (2014).

Os professores, a partir de suas vivências profissionais e de sala de aula, inventam e reinventam suas metodologias e estratégias de ensino, engendrando conteúdos escolares com conhecimentos científicos em diferentes realidades e grupos, transformando-os e produzindo saberes e fazeres. Estes, ao serem socializados nos Encontros sobre o Poder Escolar entre os pares e, também, com futuros professores, qualificam o processo de formação, bem como abrem espaço para uma reflexão individual e coletiva a respeito do que é possível e fundamental no fazer pedagógico.

Acreditamos que um desafio para a qualificada permanência do evento de formação continuada de professores, no que se refere ao ensino de Geografia, é o investimento nas reflexões e estudos sobre modos e formas de pensamento e ação nos processos de ensino e aprendizagem, aprimorando a compreensão da realidade a partir dos fenômenos espaciais.

\section{REFERÊNCIAS}

ANGROSINO, M. Etnografia e observação participante. Porto Alegre: Artmed, 2009.

CAVALCANTI, L. de S. Bases teórico-metodológicas da Geografia: uma referência para a formação e a prática de ensino. In: CAVALCANTI, L. de S. (org.). Formação de professores: concepções e práticas em Geografia. Goiânia: Editora Vieira, 2006. p. 27-49.

CAVALCANTI, L. de S. Desafios da didática de Geografia. Goiânia: Ed. da PUC, Goiás, 2013.

CORSETTI, B. A análise documental no contexto da metodologia qualitativa: uma abordagem a partir da experiência de pesquisa do Programa de Pós-Graduação em Educação da Unisinos. Unirevista, vol. 1, n 1, p.32-46. 2006.

ENCONTRO ESTADUAL SOBRE O PODER ESCOLAR, 1., 2001, Pelotas, Anais... Pelotas: 2001.70p 
ENCONTRO ESTADUAL SOBRE O PODER ESCOLAR, 2., 2002, Pelotas, Anais... Pelotas: 2002.75p

ENCONTRO ESTADUAL SOBRE O PODER ESCOLAR, 3., 2003, Pelotas, Anais ... Pelotas: 2003.74p.

ENCONTRO SOBRE O PODER ESCOLAR, 4.; Seminário Interinstitucional de Educação, 5., 2004, Pelotas. Anais... Pelotas: EGUFPEL, 2004. 176 p.

ENCONTRO SOBRE O PODER ESCOLAR. 5.; Seminário Interinstitucional de educação, 6., 2005, Pelotas, Anais... Pelotas: UFPEL, 2005. 181p.

ENCONTRO SOBRE O PODER ESCOLAR, 6.; Seminário Interinstitucional de Educação, 7., 2006, Pelotas, Anais... Pelotas: Ed. e Gráfica UFPel, 2006. 286p.

ENCONTRO SOBRE O PODER ESCOLAR, 7.; Seminário Interinstitucional de Educação, 8., 2007, Pelotas, Anais... Ed. e Gráfica UFPel, 2007. 253p.

ENCONTRO SOBRE O PODER ESCOLAR, 8., Pelotas, Anais... Pelotas: Editora da UfPel, 2008. $255 p$.

ENCONTRO SOBRE O PODER ESCOLAR, 9., Pelotas, Anais... Pelotas: Ed. da UFPel, 2009. 250p.

ENCONTRO SOBRE O PODER ESCOLAR, 10., Pelotas, Anais... Pelotas: Ed. da UfPel, 2010.240p.

ENCONTRO SOBRE O PODER ESCOLAR, 11., Pelotas, Anais... Pelotas: Ed. da UFPel, 2012. 309p. Disponível em http://wp.ufpel.edu.br/poderescolar/

ENCONTRO SOBRE O PODER ESCOLAR, 12., Pelotas, Anais...Pelotas: Ed. da UFPel, 2015. 229p.Disponível em http://wp.ufpel.edu.br/poderescolar/

FAZENDA, I. C. A. A Interdisciplinaridade: um projeto em parceria. São Paulo: Loyola, 1993.

FAZENDA, I. C. A (org.) Didática e interdisciplinaridade. São Paulo: Papirus, 1998.

FULLAN, M.; HARGREAVES, A. A escola como organização aprendente: buscando uma educação de qualidade. Porto Alegre: Artes Médicas Sul, 1999.

GATTI, B. A. Análise das políticas públicas para formação continuada no Brasil na última década. Revista Brasileira de Educação, v.13, n.37, p. 57-70, 2008.

LUCK, H. Pedagogia da interdisciplinaridade. Fundamentos teórico-metodológicos. Petrópolis: Vozes, 2001.

NÓVOA, A. O passado e o presente dos professores. In: NÓVOA, A. (org.) Profissão professor. $2^{\mathrm{a}}$ ed. Porto (Portugal): Porto Editora, 1999. p.13-34.

OLIVEIRA, D. A. O trabalho docente na América Latina: identidade e profissionalização. Retratos da Escola, Brasília, v. 2, n. 2/3, p. 29- 39, 2008. 
OLIVEIRA, D. A.; DUARTE, A. Política Educacional como política social: uma nova regulação da pobreza. Perspectiva, Florianópolis, v. 23, n. 2, p. 279-302, jul. 2005.

PIMENTA, S. G. O pedagogo na escola pública. São Paulo: Loyola, 1988

PIMENTA, S. G. Formação de professores: identidade e saberes da docência. In: PIMENTA, S. G. (org.) Saberes Pedagógicos e Atividade Docente. São Paulo: Cortez, 2000. p. 15-34.

PIMENTEL, A. O método da análise documental: seu uso numa pesquisa historiográfica. Paraná: Cadernos de Pesquisa, n.114, p.179-195, novembro, 2001.

SACRISTAN, J. G. Consciência e Acção sobre a prática como libertação profissional dos professores. In: NÓVOA, A. (org.) Profissão Professor. 2 ed.: Porto (Portugal): Porto Editora, 1999. p. 63-92.

SCHEIBE, L. Formação de professores no Brasil. Retratos da Escola, Brasília, v. 2, n. 2/3, p. 41 $54,2008$.

SILVA, J. R.; DALLIGNA, M. A. Histórias e memórias do Poder Escolar. In: CARLOS, L. C.; PEREIRA, D. A. (orgs.) Encontro sobre o Poder Escolar: formação de professores, trabalho docente e educação democrática. Pelotas: Ed. da UFPel, 2018. p. 12-19.

SHULMAN, L. S. Conhecimento e ensino: fundamentos para a nova reforma. Cadernos Cenpec, São Paulo, v.4, n.2, p.196-229, dez. 2014.

TARDIF, M.; LESSARD, C.; LAHAYE, L. Esboço de uma problemática do saber docente. Teoria \& Educação. v. 1, n. 4, p. 215-253, 1991.

TARDIF, M. Saberes docentes e formação profissional. 17. Ed. Petrópolis: Ed. Vozes, 2014.

\section{1 - Letícia Fonseca da Silva}

Professora da Rede Municipal de Pelotas, Mestre em Geografia https://orcid.org/0000-0002-2026-712X•letyedu@hotmail.com

Contribuição: Investigação, Escrita - Primeira Redação

\section{2 - Lígia Cardoso Carlos}

Professora da Universidade Federal de Pelotas, Doutora em Educação

https://orcid.org/0000-0002-6106-4150•li.gi.c@hotmail.com

Contribuição: Supervisão, Escrita - Revisão e Edição 


\section{Como citar este artigo}

SILVA, F., Letícia da, CARLOS, C., Ligia. Professores e suas experiências pedagógicas: estudo sobre a Geografia em um evento de formação continuada no sul do RS. Geografia Ensino \& Pesquisa, Santa Maria, v. 25, e14, p. 01-26, 2021. DOI 10.5902/2236499443472. Disponível em: https://doi.org/10.5902/2236499443472. Acesso em: dia mês abreviado. ano. 